UDC 347.77

LBC 67.404

\title{
NAME AS MEANS OF INDIVIDUALIZATION OF GOODS (WORKS, SERVICES) IN BUSINESS
}

\author{
Alexey V. Kopyev \\ Volgograd State University, Volgograd, Russian Federation
}

\begin{abstract}
Introduction: having features that allow recognizing the goods on the market, a trademark is of importance in achieving the objectives of business and other economic activities. One of these features is the name. It is the name that makes it possible to personalize the trademark of a mass of other similar products. Business is actively producing intellectual property in the form of a trademark using the name. In the study there has been set the goal to investigate the using and protecting of the name in the trademark. Methods: the methodological framework of this study is made up of a set of the methods of scientific knowledge, among which the main are the methods of analysis, legal formalism, synthesis, systematic and comparative law. Results: in the article the author investigates the question of the exclusive rights to the trademark in the event of using the name, analyzes the grounds of admissibility and the conditions of the name use in the trademark in business, provides the administrative and judicial justification of law enforcement. The study contains the author's position on the basis of the current legislation in the field of intellectual property and the law enforcement practice. On the basis of the legal analysis of the acts of Rospatent and the court, the author raises the questions of the efficient use and protection of the name in the trademark. Conclusions: the study has revealed the conditions of the name use in the trademark, the conditions for granting legal protection and subsequent protection of exclusively the trademark, which used the name, the application features of the priority of the legal protection. It has been proved that if the trademark has no distinctive feature, it can be freely used by different economic transactors.

Keywords: exclusive rights, trademark, name, Rospatent, character, unfair competition, intellectual property, product, legal protection.
\end{abstract}

УДК 347.77

ББК 67.404

\section{ИМЯ КАК СРЕДСТВО ИНДИВИДУАЛИЗАЦИИ ТОВАРОВ (РАБОТ, УСЛУГ) В ПРЕДПРИНИМАТЕЛЬСКОЙ ДЕЯТЕЛЬНОСТИ}

\author{
Алексей Владимирович Копьев \\ Волгоградский государственный университет, г. Волгоград, Российская Федерация
}

\begin{abstract}
Введение: товарный знак, обладая признаками, позволяющими узнавать товар на рынке, имеет значение в достижении целей предпринимательской и иной хозяйственной деятельности. Одним из таких признаков является его название. Именно оно позволяет индивидуализировать товарный знак из массы других аналогичных товаров. Бизнес активно производит интеллектуальную собственность в виде товарных знаков с использованием имени. В работе поставлена цель исследования использования и защиты имени в товарном знаке. Методы: методологическую основу данного исследования составляет совокупность методов научного познания, среди которых основное место занимают методы анализа, юридического формализма, синтеза,

- системности и сравнительно-правовой. Результаты: в статье исследуются вопросы исключительных прав на товарный знак в случае использования имени, анализируются основания допустимости и условия использования имени в товарном знаке в предпринимательской деятельности, приводятся административные и судебные обоснования правоприменения. Исследование содержит авторскую позицию исходя из норм действую仓ै щего законодательства в области интеллектуальной собственности и практики правоприменения. На основании правового анализа актов Роспатента и суда поднимаются вопросы эффективного использования и защиты имени в товарном знаке. Выводы: в результате исследования выявлены условия использования имени в
\end{abstract}


товарном знаке, условия предоставления правовой охраны и последующей защиты исключительного права на товарный знак, в котором использовано имя, особенности применения приоритета правовой охраны. Установлено, что если товарный знак не обладает различительной способностью, он может быть свободно использован различными хозяйственными субъектами.

Ключевые слова: исключительные права, товарный знак, имя, Роспатент, характер, недобросовестная конкуренция, интеллектуальная собственность, товар, правовая охрана.

\section{Введение}

Правомерное использование товарного знака, содержащего образ или имя персонажа, подтверждается свидетельством о государственной регистрации товарного знака. Регистрацию осуществляет Роспатент. Правообладатель товарного знака, используя персонаж при индивидуализации товаров в предпринимательской деятельности, должен своевременно получить разрешение от правообладателя авторских прав на произведение. После легализации своего права на использование в товарном знаке персонажа он вправе заключать гражданско-правовые договоры, связанные с использованием товарного знака, например, договор коммерческой концессии, лицензионный договор об использовании товарного знака [7].

\section{Персонаж в товарном знаке}

Использование персонажа в товарном знаке вызывает интерес ввиду экономической выгоды, получаемой от такого использования, особенно в области автомобильного бизнеса и моды [6]. Споры о правомерном использовании персонажа в товарном знаке возникают между предпринимателями и разрешаются в судебном порядке.

В суд был предъявлен иск о нарушении прав на товарный знак «Обломов» (зарегистрирован 11 октября 2000 г.) ООО «ИБГ \& Ко», владеющим рестораном «Обломов» на Пятницкой, к ООО «Позитив М», управляющему рестораном «Обломовъ на Пресне».

Ответчик (А. Табаков как владелец «Обломовъ на Пресне») указал, что вывеска ресторана «Обломовъ на Пресне» является авторским произведением Александра Адабашьяна, который в 1999 г. передал ресторану все имущественные права на его использование. Кроме того, Табаков-старший создал образ Ильи Ильича в известном фильме «Не- сколько дней из жизни Обломова». Суд счел эти показания несостоятельными, но вынес решение об аннулировании торгового знака «Обломов». Фамилия персонажа произведения И.А. Гончарова является культурным достоянием России. Вместе с тем использование ее на вывеске ресторана в связи с отсутствием прав на товарный знак и истечением срока правовой охраны на произведение литературы стало возможным как для истца, так и ответчика [1; 5].

\section{Особенности использования имени в товарном знаке}

Использование имени в товарном знаке имеет свои особенности. В соответствии с абз. 2 п. 9 ст. 1483 ГК РФ не могут быть зарегистрированы в качестве товарных знаков обозначения, тождественные имени, псевдониму или производному от них обозначению, портрету или факсимиле известного в РФ на дату подачи заявки лица, без согласия этого лица или его наследника.

Ведущий телепрограммы «Говорим и показываем с Леонидом Закошанским» Л.В. Закошанский выразил согласие на регистрацию одноименной программы товарного знака [14].

Роспатент в одном из решений указал, что маркировка товаров именем великих людей преследует цель их популяризации и сохранения памяти, что согласуется с общественными интересами и не противоречит им [9]. Ситуация возникла в связи с отказом в государственной регистрации товарного знака на словесное обозначение «DOSTOEVSKIY», которое относится к фамилии известного русского писателя Ф.М. Достоевского. Она является достоянием истории и культуры Российской Федерации, воспроизведение которой не этично, поэтому регистрация заявленного обозначения противоречит общественным интересам [15]. 
В мае 2010 г. было подано возражение ООО «Русские Традиции» на решение Роспатента от 12 февраля 2010 г. об отказе в государственной регистрации товарного знака. В частности, заявитель отметил, что правоприменительная практика Роспатента показывает следующее: были зарегистрированы такие товарные знаки, как «Tchaikovski», «Волконский», «Есенин», «Пушкин», а также то, что Государственный литературно-мемориальный музей Ф.М. Достоевского выразил согласие на регистрацию заявленного обозначения на имя заявителя. Таким образом, Роспатент дал согласие на регистрацию товарного знака «DOSTOEVSKIY» в отношении товаров 33 класса МКТУ: «алкогольные напитки, а именно: бренди; коньяк» на имя заявителя.

В соответствии со ст. 1483 ГК РФ установлены основания для отказа в государственной регистрации товарного знака. В частности, не допускается государственная регистрация в качестве товарных знаков обозначений, представляющих собой или содержащих элементы, способные ввести в заблуждение потребителя относительно товара либо его изготовителя. Заявление на регистрацию подало юридическое лицо с указанием на достаточно распространенную фамилию «Поляков». В регистрации отказали. Были внесены изменения, благодаря которым словесный элемент «Поляков» перестал быть доминирующим. Товарный знак зарегистрировали [6].

Роспатент отказал в регистрации словесного обозначения «Сталин» в качестве товарного знака, мотивировав это тем, что заявитель не представил согласие наследников И.В. Сталина. Суд согласился с этими доводами, но посчитал неубедительными рассуждения о том, что размещение товарного знака «Сталин» на алкогольных напитках может оскорбить часть населения, приверженного коммунистическим идеалам, а также ту часть населения, которая пострадала от репрессий, связанных с личностью Сталина. При этом указал, что они не подтверждены документально [8].

\section{Степень смешения товарных знаков} как признак введения в заблуждение

Достаточно часто возникают случаи сходства товарных знаков до степени смеше- ния. В одном из них в качестве товарного знака заявлено словесное обозначение «СОЛОДОВ». Это обозначение не несет в себе каких-либо указаний относительно товара или его изготовителя, позволяющих прийти к выводу о том, что российским потребителем оно воспринимается как вводящее потребителя в заблуждение. Сходство заявленного обозначения с противопоставленными товарными знаками обусловлено наличием в них фонетически и семантически тождественного словесного элемента «СОЛОДОВ», занимающего в них доминирующее положение. Таким образом, учитывая высокую степень сходства заявленного обозначения с противопоставленным товарным знаком, следует признать эту услугу однородной, поскольку эти товары и услуги тесно связаны друг с другом. В целом заявленное обозначение «СОЛОДОВ» в отношении однородных товаров и услуг вызывает сходные ассоциации с противопоставленными товарными знаками, несмотря на отдельные отличия, что обусловливает общий вывод о сходстве сравниваемых обозначений до степени смешения [10].

Индивидуализация товаров в предпринимательской деятельности играет важную роль в повышении конкурентоспособности товаров. Использование товарного знака с нарушением установленных требований способно привести к недобросовестной конкуренции. На регистрацию могут поступать заявки комбинированных обозначений, например, «ВОЛКОВ», «КРЕСТЬЯНСКОЕ ХОЗЯЙСТВО» и «А.П. Волкова». В заключении Роспатент отмечает, что элемент «КРЕСТЬЯНСКОЕ ХОЗЯЙСТВО» является неохраноспособным, а элемент «А.П. Волкова» представляет собой распространенную фамилию и инициалы, в силу чего они имеют лишь второстепенное значение при сравнении заявленного обозначения с противопоставленными товарными знаками. Следует отметить, что в данном обозначении доминирует именно слово «ВОЛКОВ», которое акцентирует на себе внимание, поскольку оно занимает центральное положение, запоминается легче, чем изобразительные элементы, и выполнено более крупным шрифтом, чем иные словесные элементЫ - «КРЕСТЬЯНСКОЕ ХОЗЯЙСТВО» и «А.П. Волкова». Словесный элемент «КРЕС- 


\section{ВОПРОСЫ ЧАСТНОПРАВОВОГО РЕГУЛИРОВАНИЯ}

ТЬЯНСКОЕ ХОЗЯЙСТВО» является неохраноспособным, поскольку представляет собой видовое наименование предприятия (п. 1 ст. 1483 ГК). Таким образом, исходя из анализа соответствующих перечней товаров и услуг коллегия Палаты по патентным спорам пришла к выводу о существовании принципиальной возможности возникновения у потребителя представления о принадлежности вышеуказанных товаров и услуг одному производителю [12].

Недопустимо при предоставлении исключительного права одному субъекту допускать нарушение прав иных участников торгового оборота, на это указал Роспатент при рассмотрении возражения ООО «Мусихин. Мир меда» (Оренбург). В качестве товарного знака заявлено комбинированное обозначение, представляющее собой изображение стилизованной печати, в центре которой расположено изображение пчелы, а по кругу - словесные элементы «МУСИХИН МИР МЕДА», выполненные оригинальным шрифтом буквами русского алфавита. Правовая охрана испрашивается в сочетании оранжевого и белого цветов. Исходя из представленных документов общество осуществляет деятельность в области производства и реализации башкирского меда под обозначением «Мир меда» начиная с 2008 г.; является администратором сайтов, включающих обозначение «mir meda»; под обозначением «Мусихин. Мир меда» участвовал в специализированных выставках, имеет награды. Вместе с тем в сети Интернет действуют сайты различных участников гражданского оборота, использующих обозначение «Мир меда» в своей деятельности: на ВВЦ проводятся ярмарки «Мир меда», в городе Слуцке проводятся ярмарки «Мир меда и здоровья» (http://www.beelife.org/jarmarkameda/mir-meda-i-zdorovja-g-sluck.html), существует онлайн-игра «Мир меда», в которой надо добывать и реализовывать мед (www. itsmygame.ru), сайт с тождественной различительной частью mirmeda - www.mirmeda.biz, который не относится к заявителю.

Таким образом, словосочетание «Мир меда» не обладает различительной способностью и нуждается в свободном использовании различными хозяйственными субъектами при производстве меда [11].

\section{Выводы}

Таким образом, следует отметить, что не все споры разрешаются при помощи административного ресурса [4]. Возникшие разногласия между ОАО «Московская кондитерская фабрика «Красный Октябрь» (Москва) и ОАО «Оркла Брэндс Россия» как правопреемник кондитерской фабрики им. Крупской, которое приобрело оспариваемый товарный знак у ООО «Кондитерский комбинат «Азарт» (Санкт-Петербург) по договору отчуждения исключительного права на товарный знак «МЕЧТА АЛЕНКИ», в конечном итоге разрешились прекращением производства по делу. ОАО «Московская кондитерская фабрика «Красный Октябрь» представило ходатайство от 25 октября 2013 г., содержащее просьбу об отзыве возражения против предоставления правовой охраны товарному знаку [6].

В настоящее время вопросы использования имени (персонажа) в товарном знаке приобретают большую популярность, предприниматели стали заинтересованы в поддержании известности средствами индивидуализации таким способом, о чем свидетельствует правоприменительная практика [2;3].

\section{СПИСОК ЛИТЕРАТУРЫ}

1. Имя Обломова до сих пор чистое и неприкосновенное. - Электрон. текстовые дан. - Режим доступа: http://pattrade.ru/about/stories/81 (дата обращения: 26.09.2016). - Загл. с экрана.

2. Иншакова, А. О. Правовое регулирование интеллектуальной собственности в перечне законодательных приоритетов обеспечения наноиндустрии / А. О. Иншакова // Вестник Федерального арбитражного суда Северо-Кавказского округа. 2012. - № 1. - C. 45-52.

3. Иншакова, А. О. Реализация эффективной конкурентной политики ЕС в сфере инноваций посредством общего интеллектуального права / А. О. Иншакова, Д. В. Кожемякин // Законы России: опыт, анализ, практика. -2013. -№ 2. - С. 19-23.

4. Копьев, А. В. Информационный посредник как субъект гражданско-правовой ответственности / А. В. Копьев // Вестник Волгоградского государственного университета. - 2013. - № 3. - С. 74-78.

5. «Персонаж» в роли самостоятельного объекта авторского права или коммерческого использования. - Электрон. текстовые дан. - Режим доступа: http://www.copyright.ru/ru/documents/ 
avtorskoe_pravo/pravoobladateli/character/ (дата обращения: 26.09.2016). - Загл. с экрана.

6. Погребинская, Т. Ю. Товарные знаки - фамилии: некоторые вопросы правовой охраны в РФ / Т. Ю. Погребинская. - Доступ из информ.-правового портала «Гарант», 2013.

7. Рахманина, Н. В. Понятие Интернета и проблемы, связанные с оказанием финансовых интернет-услуг / Н. В. Рахманина // Вестник Волгоградского государственного университета. - 2015. - № 4 (29). - C. 107-113.

8. Робинов, А. Отказ в правовой охране товарным знакам, противоречащим общественным интересам, принципам гуманности и морали / А. Робинов // Интеллектуальная собственность. Промышленная собственность. - 2009. - № 1. - С. $34-42$.

9. Товарный знак: где границы морали? Электрон. текстовые дан. - Режим доступа: http:// www.gorodissky.ru/publications/articles/?newsid=324 (дата обращения: 26.09.2016). - Загл. с экрана.

10. Федеральный институт промышленной собственности (ФИПС). - Электрон. текстовые дан. - Режим доступа: http://www.fips.ru/pps/ 12_11_13/2013В00822_13.1.213.pdf(дата обращения: 26.09.2016). - Загл. с экрана.

11. Федеральный институт промышленной собственности (ФИПС). - Электрон. текстовые дан. - Режим доступа: http://www.fips.ru/pps/ 21_11_13/2013B01199_22.1.213.pdf(дата обращения: 26.09.2016). - Загл. с экрана.

12. Федеральный институт промышленной собственности (ФИПС). - Электрон. текстовые дан. - Режим доступа: http://www.fips.ru/pps/ 29_11_13/2013B01051_02.1.213.pdf(дата обращения: 26.09.2016). - Загл. с экрана.

13. Федеральный институт промышленной собственности (ФИПС). - Электрон. текстовые дан. - Режим доступа: http://www.fips.ru/pps/ 2911 13/2013В01425 02.1.213.pdf(дата обращения: 26.09.2016). - Загл. с экрана.

14. Федеральный институт промышленной собственности (ФИПС). - Электрон. текстовые дан. - Режим доступа: http://www.fips.ru/pps/ 29_11_13/2013B01501_02.1.213.pdf(дата обращения: 26.09.2016). - Загл. с экрана.

15. Федеральный институт промышленной собственности (ФИПС). - Электрон. текстовые дан. - Режим доступа: http://www.fips.ru/pps/ 31_08_10/2008725433_20100906.pdf(дата обращения: 26.09.2016). - Загл. с экрана.

\section{REFERENCES}

1. Imya Oblomova do sikh por chistoe $i$ neprikosnovennoe [Oblomov's Name Is Still Clear and
Inviolable]. Available at: http://pattrade.ru/about/ stories/81 (accessed 26 September 2016).

2. Inshakova A.O. Pravovoe regulirovanie intellektualnoy sobstvennosti $\mathrm{v}$ perechne zakonodatelnykh prioritetov obespecheniya nanoindustrii [Legal Regulation of Intellectual Property Is in the List of Legislative Priorities to Ensure Nanotechnology Industry]. Vestnik Federalnogo arbitrazhnogo suda Severo-Kavkazskogo okruga, 2012, no. 1, pp. 45-52.

3. Inshakova A.O., Kozhemyakin D.V. Realizatsiya effektivnoy konkurentnoy politiki ES v sfere innovatsiy posredstvom obshchego intellektualnogo prava [Implementation of Effective Competition Policy of the EU in the Field of Innovation Through a Common Intellectual Right]. Zakony Rossii: opyit, analiz, praktika, 2013, no. 2, pp. 19-23.

4. Kopyev A.V. Informatsionnyiy posrednik kak subyekt grazhdansko-pravovoy otvetstvennosti [Informational Intermediary as a Subject of Civil Liability]. Vestnik Volgogradskogo gosudarstvennogo universiteta. Seriya 5, Yurisprudentsiya [Science Journal of Volgograd State University. Jurisprudence], 2013, no. 3, pp. 74-78.

5. «Personazh» v roli samostoyatelnogo obyekta avtorskogo prava ili kommercheskogo ispolzovaniya ["Character" as an Independent Object of Copyright or Commercial Use]. Available at: http://www.copyright.ru/ ru/documents/avtorskoe_pravo/pravoobladateli/ character/ (accessed September 26, 2016).

6. Pogrebinskaya T.Yu. Tovarnye znakifamilii: nekotorye voprosy pravovoy okhrany $v R F$ [Trademarks - Surnames: Some Issues of Legal Protection in the Russian Federation]. Access from Information Legal Portal "Garant”, 2013.

7. Rakhmanina N.V. Ponyatie Interneta i problemy, svyazannye s okazaniem finansovykh internet-uslug [The Concept of the Internet and the Problems Associated with the Provision of Online Financial Services]. Vestnik Volgogradskogo gosudarstvennogo universiteta. Seriya 5, Yurisprudentsiya [Science Journal of Volgograd State University. Jurisprudence], 2015, no. 4, pp. 107-113.

8. RobinovA. Otkaz v pravovoy okhrane tovarnym znakam, protivorechashchim obshchestvennym interesam, printsipam gumannosti i morali [Reject of Legal Protection of Trademarks Abusing Public Interests, Principles of Humanity and Morality]. Intellektualnaya sobstvennost, 2009, no. 1, pp. 34-42.

9. Tovarnyy znak: gde granitsy morali? [Trademark: Where Are the Boundaries of Morality?]. Available at: http://www.gorodissky.ru/publications/ articles/?newsid=324. (accessed September 26, 2016).

10. Federalnyy institut promyshlennoy sobstvennosti (FIPS) [Federal Institute of Industrial Property (FIPS)]. Available at: http://www.fips.ru/pps/ 


\section{ВОПРОСЫ ЧАСТНОПРАВОВОГО РЕГУЛИРОВАНИЯ}

12_11_13/2013B00822_13.1.213.pdf. (accessed September 26, 2016).

11. Federalnyy institut promyshlennoy sobstvennosti (FIPS) [The Federal Institute of Industrial Property(FIPS)]. Available at: http://www.fips.ru/pps/21_11_13/ 2013B01199_22.1.213.pdf. (accessed September 26, 2016).

12. Federalnyy institut promyshlennoy sobstvennosti (FIPS) [The Federal Institute of Industrial Property (FIPS)]. Available at: http:// www.fips.ru/pps/21_11_13/2013B01199_22.1.213.pdf. (accessed September 26, 2016).

13. Federalnyy institut promyshlennoy sobstvennosti (FIPS) [The Federal Institute of
Industrial Property (FIPS)]. Available at: http:// www.fips.ru/pps/29_11_13/2013B01051_02.1.213.pdf. (accessed September 26, 2016).

14. Federalnyy institut promyshlennoy sobstvennosti (FIPS) [The Federal Institute of Industrial Property (FIPS)]. Available at: http:// www.fips.ru/pps/29_11_13/2013B01425_02.1.213.pdf. (accessed September 26, 2016).

15. Federalnyy institut promyshlennoy sobstvennosti (FIPS) [The Federal Institute of Industrial Property (FIPS)]. Available at: http:// www.fips.ru/pps/31_08_10/2008725433_20100906.pdf. (accessed September 26, 2016).

\section{Information About the Author}

Alexey V. Kopyev, Candidate of Juridical Sciences, Associate Professor, Assistant Professor, the Department of Civil and International Private Law, Volgograd State University, the Base Department of Southern Scientific Center of the Russian Academy of Sciences, Prosp. Universitetsky, 100, 400062 Volgograd, Russian Federation, gimchp@volsu.ru.

\section{Информация об авторе}

Алексей Владимирович Копьев, кандидат юридических наук, доцент, доцент кафедры гражданского и международного частного права, Волгоградский государственный университет, базовая кафедра ЮНЦ РАН, просп. Университетский, 100, 400062 г. Волгоград, Российская Федерация, gimchp@volsu.ru. 